\title{
Congratulations to the Archives of Plastic Surgery
}

\section{Tor Wo Chiu}

Council Member of the Hong Kong Society of Plastic, Reconstructive and Aesthetic Surgeons Section Editor, Archives of Plastic Surgery

Plastic Reconstructive and Aesthetic Surgery, Chinese University of Hong Kong, Hong Kong SAR, China

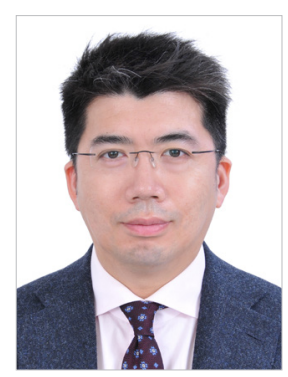

Plastic surgery in Hong Kong began at a rudimentary level in the early 1960s with doctors who had acquired some training overseas, particularly the UK and the US, and then returned to Hong Kong. Things then progressed at an accelerated pace, and by 1967, the Hong Kong Society of Plastic, Reconstructive and Aesthetic Surgeons was founded. It is a non-profit organization established with the aim of promoting education, training, and research in the field. Over more than half a century, the Society has contributed a great deal to the development of plastic surgery in Hong Kong. As part of its commitment to regular continuing medical education meetings, the Society has organized conferences and invited numerous overseas experts to give lectures.

We are delighted to partner with Archives of Plastic Surgery, as well as the other regional societies that now all have a stake in the success of this journal. We congratulate the editorial board on this most worthwhile endeavor. This is sure to take us all to another level.

\section{NOTES}

\section{Conflict of interest}

Tor Wo Chiu is an editorial board member of the journal but was not involved in the peer reviewer selection, evaluation, or decision process of this article. No other potential conflicts of interest relevant to this article were reported.

\section{ORCID}

Tor Wo Chiu https://orcid.org/0000-0001-9968-1050
Correspondence: Tor Wo Chi

Plastic Reconstructive Surgery, Chinese University of Hong Kong, 4th Floor, Clinical Sciences building, Prince of Wales Hospital, Shatin, Hong Kong SAR, China

Tel: +852-35052639, Fax: +852-26377974, E-mail: torchiu@surgery.cuhk.edu.hk

Received: May 11, $2021 \bullet$ Revised: May 12, $2021 \bullet$ Accepted: May 13, 2021

pISSN: 2234-6163・ elSSN: 2234-6171

https://doi.org/10.5999/aps.2021.00794 • Arch Plast Surg 2021;48:245 